\title{
DNA-binding properties of the HMG domain of the lymphoid-specific transcriptional regulator LEF-1
}

\author{
Klaus Giese,, Adam Amsterdam, ${ }^{1}$ and Rudolf Grosschedl \\ Howard Hughes Medical Institute, Departments of Microbiology and Biochemistry, University of California, \\ San Francisco, California 94143-0414 USA
}

\begin{abstract}
Lymphoid enhancer-binding factor 1 (LEF-1) is a pre-B and T lymphocyte-specific nuclear protein that participates in the regulation of the T-cell antigen receptor (TCR) $\alpha$ enhancer by binding to the nucleotide sequence $5^{\prime}$-CCTTTGAA. LEF-1 protein shares with the nonhistone high mobility group protein 1 (HMG-1) and several transcriptional regulators a single region of amino acid homology, termed the HMG box, which has been implicated in DNA binding. Here, we report the biochemical analysis of the interaction of this novel structural motif with DNA. First, amino- or carboxy-terminal truncations of the LEF-1 polypeptide delineated the HMG box as the DNA-binding domain. We purified to homogeneity a LEF-HMG domain peptide expressed in Escherichia coli and determined the equilibrium constant for specific binding to DNA as $1 \times 10^{-9} \mathrm{M}$. Second, cotranslation of wild-type and various truncated LEF-1 polypeptides did not generate any DNA-binding heterodimers, suggesting that LEF-1 can bind DNA as a monomer. Third, methylation interference analysis indicated that the HMG domain specifically contacts DNA on one side of the double helix. Finally, changes of amino acids that are conserved among various members of the family of HMG-box proteins decreased the affinity of DNA binding by one to three orders of magnitude. Together, these data define the characteristics of specific DNA-binding by the HMG domain of LEF-1.
\end{abstract}

[Key Words: Enhancer-binding factor; HMG-box protein; LEF-1; lymphoid-specific gene expression]

Received September 9, 1991; revised version accepted October 25, 1991.

Comparisons of amino acid sequences of protein domains involved in DNA binding have demonstrated an evolutionary conservation of distinct structural motifs (for review, see Johnson and McKnight 1989; Mitchell and Tjian 1989). Well-characterized structural features of DNA-binding domains include the helix-turn-helix homeo domain (Pabo and Lewis 1982; Kissinger et al. 1990), the helix-loop-helix (HLH) (Murre et al. 1989), zinc fingers (Klug and Rhodes 1987), and basic leucine zippers (bZip) (Landschulz et al. 1988). Recently, another family of DNA-binding proteins with homology to the chromosomal high mobility group protein 1 (HMG-1) has been described. This family comprises several biochemically characterized DNA-binding proteins, such as the rRNA gene promoter upstream-binding factor (hUBF; Jantzen et al. 1990), the mitochondrial DNA-binding protein mtTF1 (Parisi and Clayton 1991), the T-cell factor 1 (TCF-1; Oosterwegel et al. 1991; van de Wetering et al. 1991), and the lymphoid enhancer-binding factor 1 (LEF1; Travis et al. 1991), which has also been termed TCF$1 \alpha$ (Waterman et al. 1991). Other members include the genetically defined mammalian testis-determining factor SRY (Gubbay et al. 1990; Sinclair et al. 1990) and the

\footnotetext{
${ }^{1}$ These authors contributed equally to this work.
}

fungal mating-type proteins Mat Mc and Mt al (Kelly et al. 1988; Staben and Yanofsky 1990|. The region of homology between these proteins comprises $\sim 85$ amino acids and has been termed the HMG box (Jantzen et al. 1990). Experiments aimed at delineating the DNA-binding domains of hUBF, LEF-1/TCF-1 $\alpha$ and TCF-1 indicated that a 200-amino-acid region, including an HMG box, was able to bind DNA (Jantzen et al. 1990; Oosterwegel et al. 1991; Waterman et al. 1991). Together with the amino acid conservation, these findings suggested that the HMG box represents a DNA-binding domain.

Two features distinguish the HMG-box family from many other known DNA-binding proteins. First, the degree of sequence specificity of DNA binding varies among different members of the family. HMG-1 binds DNA in a nonspecific manner (for review, see van Holde 1989), whereas hUBF, mtTF-1, LEF-1, and TCF-1 bind specific nucleotide sequences (Jantzen et al. 1990; Parisi and Clayton 1991; Travis et al. 1991; van de Wetering et al. 1991; Waterman et al. 1991). Second, individual members of the family contain one or more of these putative DNA-binding domains. HMG-1 and hUBF, which are expressed in all cell types examined, contain two and four HMG boxes, respectively, whereas the cell typespecific proteins SRY, LEF-1, TCF-1, Mat Mc, and Mt al 
contain only a single HMG box. Therefore, questions arise as to the DNA-binding properties of these HMG boxes and how they compare with those of other structural motifs associated with transcriptional regulators.

LEF-l provides a paradigm for a developmentally regulated and sequence-specific DNA-binding protein that contains a single HMG box (Travis et al. 1991; Waterman et al. 1991). LEF-l protein is encoded by a gene located on mouse chromosome 3 and human chromosome 4 (Milatovich et al. 1991). LEF-1 transcripts can be detected only in pre-B and T lymphocytes (Travis et al. 1991). This expression pattern parallels the functional activity of a lymphoid-specific enhancer associated with the T-cell receptor (TCR) $\alpha$ gene (Ho et al. 1989; Winoto and Baltimore 1989; Travis et al. 1991). LEF-1 protein was shown to bind to the nucleotide sequence $5^{\prime}$-CTTTGAA within the TCR $\alpha$ enhancer (Travis et al. 1991; Waterman et al. 1991). Two sets of experiments indicated that LEF-1 participates in the regulation of TCR $\alpha$ enhancer function. First, mutation of the LEF-1-binding site decreased enhancer function only in cells containing LEF-1. Second, forced expression of recombinant LEF-1 in mature B cells lacking endogenous LEF-1 increased the function of a transfected TCR $\alpha$ enhancer in a LEFbinding site-dependent manner (Travis et al. 1991; Waterman et al. 1991).

In this report we attempted to gain insight into the sequence-specific DNA binding by the HMG domain of LEF-1. Our analysis of the interaction between a synthetic or purified native HMG domain peptide and DNA indicated a relatively high affinity of DNA binding and long half-life of the peptide-DNA complex. We also present evidence that the HMG domain of LEF-1 can bind specific DNA sequences as a monomer by contacting one side of the double helix. Finally, we identified amino acid residues in the HMG domain that are important for DNA binding.

\section{Results \\ Delineation of the DNA-binding domain of LEF-1}

To delineate the DNA-binding domain of LEF-1, we generated amino- and carboxy-truncated forms of the protein in vitro (Fig. 1A). Mutated LEF-1 cDNA clones carrying deletions of $5^{\prime}$ - or $3^{\prime}$-terminal sequences were inserted into a vector containing an in-frame ATG codon and a promoter for T7 RNA polymerase. $3^{\prime}$-Truncated LEF-1 CDNAs were also provided with an in-frame termination codon (see Materials and methods). The cDNA inserts were transcribed in vitro with T7 RNA polymerase, and the transcripts were translated in a wheat germ extract. The truncated LEF-1 polypeptides were examined for sequence-specific DNA binding in an electrophoretic mobility-shift assay using a labeled 25-bp duplex oligonucleotide from the human TCR $\alpha$ enhancer as a probe (Fig. 1B). This oligonucleotide, termed TCR $\alpha 25$, was shown previously to contain a binding site for LEF-1 (Travis et al. 1991). Several protein-DNA complexes were detected using the wheat germ extract programmed with LEF-1 transcripts (lane 3). The slowest-migrating complex was formed with the nearly full-length N25LEF-1 polypeptide comprising amino acids 25-397. The faster-migrating complexes most likely represent partial LEF-1 polypeptides generated by initiation of in vitro translation at internal ATG codons. Deletion of as many as 243 amino acids from the amino terminus of LEF-1 did not interfere with DNA binding (lanes 3-6). Removal of an additional 61 amino acids that include 18 within the HMG box, however, abrogated DNA binding (lane 7). Carboxy-terminal truncation of LEF-1 to amino acid 384 did not interfere with protein-DNA complex formation (lane 11), whereas LEF-1 polypeptides truncated to amino acid 365 failed to bind the DNA probe (lane 10). To examine whether all polypeptides were synthesized in comparable amounts, the transcripts derived from the various truncated LEF-1 cDNA inserts were translated in the presence of $\left[{ }^{35} S \mid\right.$ methionine and the polypeptides were analyzed by SDS-PAGE (Fig. 1C). This analysis indicated the equivalent synthesis of polypeptides from the various mutated LEF-1 cDNAs. Taken together, the data delineate the DNA-binding domain of LEF-1 to between amino acids 244 and 384 and indicate that the region of homology with the other HMG box proteins is necessary for DNA binding.

Many DNA-binding proteins contain structural features that allow for protein-protein oligomerization. In particular, the leucine zipper of the bZip class of proteins provides a structural frame for dimerization that is also necessary for DNA binding (Landschulz et al. 1989; Turner and Tiian 1989). Likewise, the basic HLH (bHLH) domain, found in various enhancer-binding factors, is required for both interaction with DNA and with itself or another member of the bHLH protein family (Davis et al. 1990; Voronova and Baltimore 1990; Sun and Baltimore 1991). To examine whether the HMG domain of LEF-1 can mediate dimerization, various amino-terminal truncated LEF-1 polypeptides were either translated individually or cotranslated with the nearly full-length N25LEF-1 polypeptide. Binding of the LEF-I polypeptides to the 25-bp TCR $\alpha$ oligonucleotide was examined in an electrophoretic mobility-shift assay (Fig. 2). The migration of the protein-DNA complexes containing cotranslated LEF-1 polypeptides (lanes 7-9) was indistinguishable from the sum of the N25-LEF-1 (lane 3) and the truncated LEF-1 polypeptides (lanes 4-6). This suggests that LEF-1 most likely binds DNA as a monomer, although we cannot rule out the possibility that LEF-1 can heterodimerize with another member of the HMG box family or with unrelated DNA-binding proteins, or even homodimerize through its amino-terminal 25 amino acids. Consistent with the putative binding of LEF-1 to the TCR $\alpha 25$ oligonucleotide as a monomer, the nucleotide sequence of the binding site has no obvious symmetry.

\section{Sequence-specific DNA binding of the LEF-HMG} domain

We extended our analysis by using two types of peptides that comprise only the HMG domain. First, we exam- 

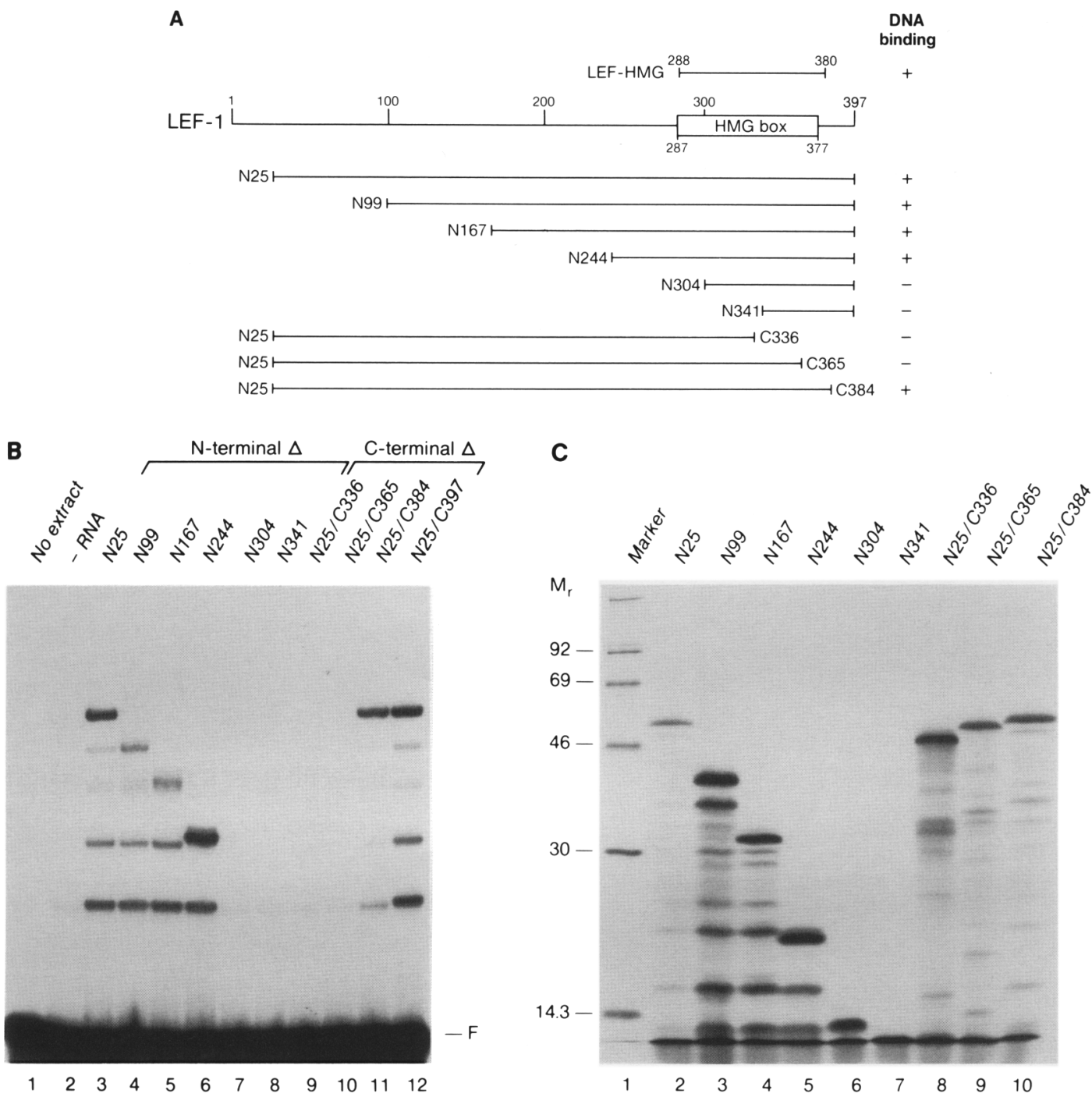

Figure 1. Delineation of the HMG box of LEF-1 as DNA-binding domain. $(A)$ Schematic summary of the structure and DNA-binding ability of deletion mutants of LEF-1. The 397-amino-acid open-reading frame is indicated by a line, with the HMG box homology represented by a box. The structures of the deletion mutants, with their amino-terminal or carboxy-terminal amino acid position denoting the deletion break point, are shown below. All carboxy-terminal deletion mutants have their amino terminus at position 25 . The structure of a 93-amino-acid synthetic peptide comprising the HMG box is shown above. The ability of the deletion mutants and the peptide to bind a LEF-binding site in an electrophoretic mobility shift assay (EMSA) is indicated by + or - symbols. $(B)$ DNA binding of LEF-1 deletion mutants in an EMSA. The amino- or carboxy-terminal truncated LEF-1 cDNA clones were transcribed in vitro, and the transcripts were translated in a wheat germ extract. The protein products were incubated with a labeled TCR $\alpha 25$ oligonucleotide (position 60-84 of the human TCR $\alpha$ enhancer; Ho et al. 1989; Travis et al. 1991) comprising a binding site for LEF-1 (lanes 3-12). The position of the free probe $(F)$ is indicated. Lanes 1 and 2 contain probe alone and probe incubated with unprogrammed wheat germ extract, respectively. (C) SDS-PAGE analysis of $\left[{ }^{35} \mathrm{~S} \mid\right.$ methionine-labeled in vitro translation products derived from various amino- or carboxy-terminal truncated LEF-1 cDNA clones. The sizes of the molecular mass markers are indicated in $\mathrm{kD}$.

ined DNA binding of a synthetic peptide containing amino acids $288-380$ of LEF-1 in a gel mobility-shift assay (Fig. 3A). A single peptide-DNA complex was detected with the TCR $\alpha 25$ oligonucleotide (lane 2). The peptide-DNA complex could be competed by addition of excess unlabeled wild-type TCR $\alpha$ oligonucleotide (lanes $3-7$ ) but not with a mutant TCR $\alpha 25$ oligonucleotide (see Materials and methods; Travis et al. 1991/ containing a triple-point mutation in the LEF-1-binding site (lanes 8-12). Binding of this peptide to a larger 98-bp TCR $\alpha$ enhancer DNA fragment was also assayed by DNase I footprinting (Fig. 3B). The addition of increasing amounts of peptide resulted in the appearance of a 14nucleotide protected region (lanes 3-7), which coincides with the footprint observed previously with intact LEF-1 protein (Travis et al. 1991). Binding of the LEF-HMG peptide to the TCR $\alpha 98$ DNA fragment also resulted in enhanced DNase I cleavage at nucleotides flanking the binding site. Together, these data indicate that the HMG box of LEF- 1 represents a primary sequence that can fold 


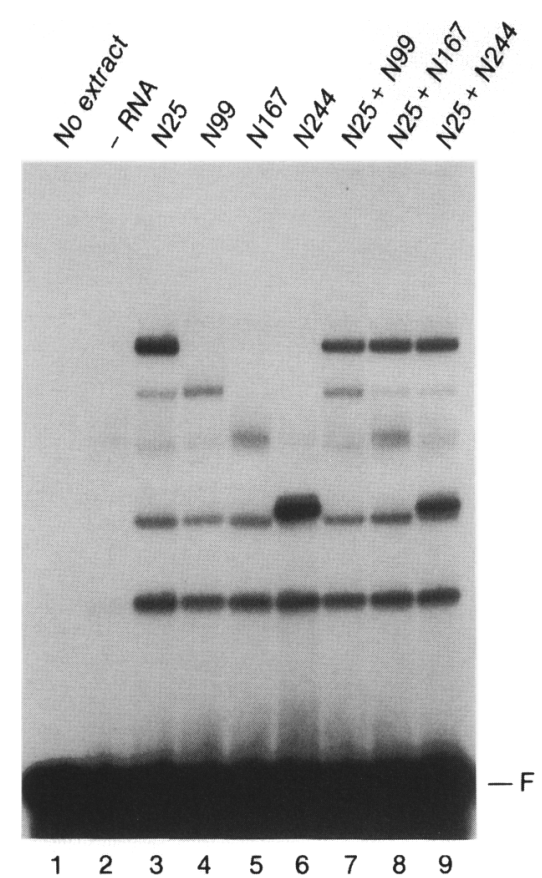

Figure 2. The HMG domain of LEF-1 binds DNA most likely as a monomer. Electrophoretic mobility shift assay of aminoterminally truncated LEF-1 polypeptides with labeled TCR $\alpha 25$ oligonucleotide was performed as described in Fig. 1. The nearly full-length N25 LEF-1 polypeptide (amino acids 25-397) and each of the truncated polypeptides were translated in vitro either in separate reactions (lanes 3-6) or cotranslated (lanes 7-9) before incubation with the probe. The position of the free probe $(F)$ is indicated.

independently of flanking amino acids to generate a sequence-specific DNA-binding domain.

Second, we used a native LEF-HMG domain peptide to determine the thermodynamic and kinetic parameters of DNA binding, because these experiments were dependent on the proper folding of virtually all peptide molecules. Toward this goal, we fused a LEF-1 cDNA fragment encoding the HMG domain to the $3^{\prime}$ end of the glutathione-S-transferase gene (GST; see Materials and methods). The fusion protein was expressed in Escherichia coli and purified by glutathione-Sepharose affinity chromatography. Because the fusion protein was soluble, no denaturation or renaturation steps were required for its purification. Cleavage of the purified fusion protein with factor Xa and ion-exchange chromatography of the products allowed for further purification of the LEF-HMG domain to near homogeneity (Fig. 4).

The equilibrium dissociation constant $\left(K_{\mathrm{d}}\right)$ for binding of the purified LEF-HMG domain to the TCR $\alpha 25$ oligonucleotide was determined by saturation-binding experiments, in which the concentration of peptide was varied relative to a fixed and limiting concentration of oligonucleotide (Fig. 5A). A graphic representation of the data indicated that the $K_{\mathrm{d}}$ for this reaction was $1 \times 10^{-9} \mathrm{M}$ at $20^{\circ} \mathrm{C}$ (Fig. $5 \mathrm{~B}$ ), assuming that all peptide molecules were able to bind DNA. A similar value for the $K_{\mathrm{d}}$ was ob- tained using an alternative experimental protocol and algorithm (Liu-Johnson et al. 1986) which, in addition, allowed us to determine the "active" fraction of total peptide as $20-50 \%$, depending on the preparation (data not shown). To estimate the specificity of DNA binding of the LEF-HMG domain, we determined the $K_{\mathrm{d}}$ of its nonspecific interaction with DNA. We used as probes for DNA binding a mutated TCR $\alpha 25$ oligonucleotide and two unrelated but similarly sized oligonucleotides, termed $m b$ and $m y b$ (see Materials and methods). The $K_{\mathrm{d}}$ for the interaction of the LEF-HMG domain with the mutant TCR $\alpha 25$ oligonucleotide was 10 -fold higher than that obtained with the wild-type TCR 25 oligonucleotide (data not shown). The $K_{\mathrm{d}}$ for binding of the unrelated oligonucleotides $\mathrm{mb}$ and myb was increased 20 and 40 -fold, respectively, relative to that of the wild-type TCR $\alpha 25$ oligonucleotide (data not shown). Therefore, the specificity of DNA binding, as defined by the ratio of $K_{\mathrm{d}}$ for "specific" DNA and $K_{\mathrm{d}}$ for "nonspecific" DNA, is at least 20 - to 40 -fold.

The dissociation rate constant $\left(k_{\mathrm{d}}\right)$ of the LEF/HMGDNA complex was obtained by measuring the stability of the complex in competition experiments (Fig. 5C). Analysis of the data indicated a $k_{\mathrm{d}}$ of $1.1 \times 10^{-4} \mathrm{sec}$ and a half-life for the complex of $120 \mathrm{~min}$. Taken together, these data suggest that the interaction between the LEFHMG domain and specific DNA is characterized by a relatively high affinity and a slow rate of dissociation.

\section{The LEF-HMG domain specifically contacts DNA on one side of the double helix}

To gain insight into the interaction of the LEF-HMG domain with its binding site, we performed a methylation interference analysis. This assay examines the steric inhibition of factor-DNA interactions by the addition of methyl groups on guanine or adenine residues. The methylation of the N7 position of guanine and the N3 position of adenine is indicative of major and minor groove contacts, respectively (Gilbert et al. 1976). The TCR $\alpha 25$ oligonucleotide was partially methylated, incubated with the synthetic or purified LEF-HMG domain, and the free and bound DNA probe was isolated, cleaved with piperidine, and separated on denaturing polyacrylamide gels (Fig. 6A and data not shown). The binding of the LEF-HMG domain to the TCR $\alpha 25$ oligonucleotide was inhibited by methylation of $\mathrm{G}_{70}$ and partially inhibited by methylation of $\mathrm{G}_{69}$ of the noncoding strand. Likewise, methylation of the $A_{71}, A_{72}$, and $A_{73}$ of the noncoding strand and $A_{75}$ and $A_{76}$ of the coding strand in terfered with binding by the HMG domain. The results of the methylation interference analysis are summarized in a projection diagram of the DNA double helix (Fig. 6B). This representation of the data shows extensive N3adenine methylation interference and suggests specific contacts of the LEF-HMG domain with one side of the DNA helix. The importance of these nucleotides for the interaction with LEF-1 protein is substantiated further by previous mutational analyses of the LEF-1-binding site in the TCR $\alpha$ enhancer. Both a double-point muta- 

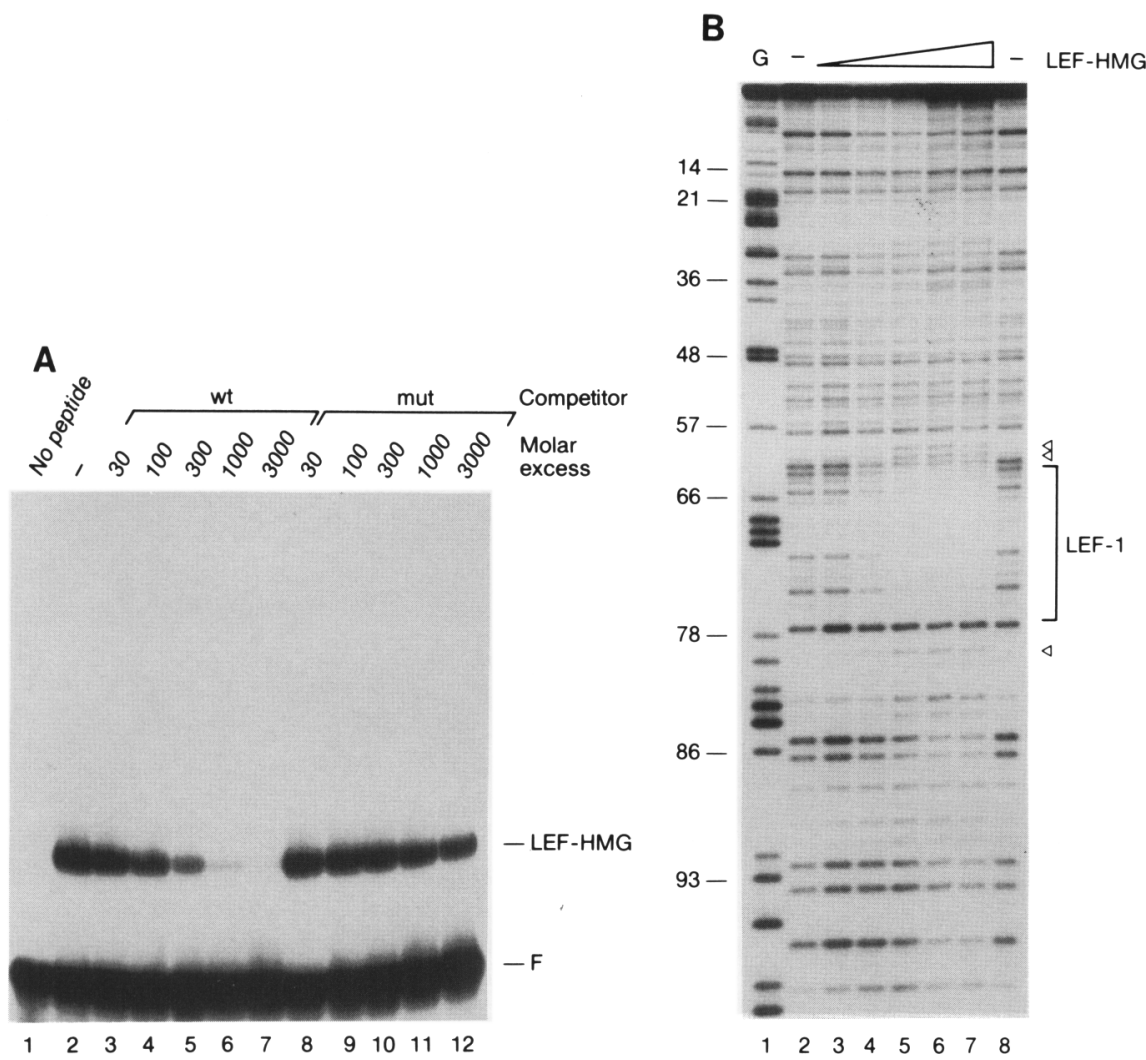

Figure 3. Sequence-specific binding of a synthetic LEF-HMG domain peptide to DNA. (A) Analysis of the specificity of LEF-HMG binding to DNA in an electrophoretic mobility shift assay. Synthetic LEF-HMG peptide (200 ng) was incubated with a labeled TCR 225 oligonucleotide probe and $100 \mathrm{ng}$ sheared salmon sperm DNA in the absence of oligonucleotide competitors (lane 2) or in the presence of wild-type (lanes 3-7) or mutated (lanes 8-12) TCR $\alpha 25$ oligonucleotide competitor. The mutant oligonucleotide contains three point mutations in the LEF-binding site (see Materials and methods; Travis et al. 1991). (B) DNase I footprint analysis of a TCR $\alpha$ enhancer DNA fragment with a synthetic peptide comprising amino acids $288-380$ of LEF-1. A 98-bp fragment from the human TCR $\alpha$ enhancer (TCR $\alpha 98$; Travis et al. 1991) was $5^{\prime}$-end-labeled on the noncoding strand and incubated with no protein (lanes 2,8 ) or with increasing amounts of LEF-HMG peptides (lanes 3-7). LEF-HMG peptides $(11,34,90$, 260 , and $1000 \mathrm{ng}$ ) were incubated with the labeled DNA probe in the presence of $2 \mu \mathrm{g}$ of poly[d(I-C)] and $2 \mu \mathrm{g}$ of salmon sperm DNA, and partially digested with DNase I. The DNase I-protected region is indicated with a bracket. Nucleotides exhibiting enhanced sensitivity to DNase I cleavage are shown by open arrowheads. Lane 1 contains a Maxam-Gilbert G nucleotide sequence reaction of the same DNA fragment.

tion of $\mathrm{A}_{71}$ and $\mathrm{A}_{73}$ and a triple-point mutation of $\mathrm{G}_{69}$, $\mathrm{G}_{70}$, and $\mathrm{C}_{74}$ in the noncoding strand abrogated DNA binding by LEF-1 and decreased TCR $\alpha$ enhancer function (Travis et al. 1991; Waterman et al 1991).

Amino acid conservation in the HMG box of LEF-1 and SRY defines residues important for DNA binding

LEF-1 shares amino acid conservation with other members of the HMG-box family. The highest degree of conservation (97\% identity) can be detected between LEF-1 and TCF-1 (Oosterwegel et al. 1991; Travis et al. 1991; van de Wetering et al. 1991; Waterman et al. 1991). Both proteins were shown to recognize the same nucleotide sequence in the TCR $\alpha$ enhancer (Oosterwegel et al. 1991; Travis et al. 1991; Waterman et al. 1991). LEF-1 also shares a lower degree of amino acid sequence homology (25\% identity and $41 \%$ similarity) with the mammalian testis-determining factor SRY (Gubbay et al. 1990; Sinclair et al. 1990). Although the specificity of DNA binding has not yet been established for SRY protein, two naturally occurring mutations in the HMG box of the human SRY gene have been linked to the sex reversal observed in XY females carrying the mutated SRY allele (Berta et al. 1990). Because these mutations change

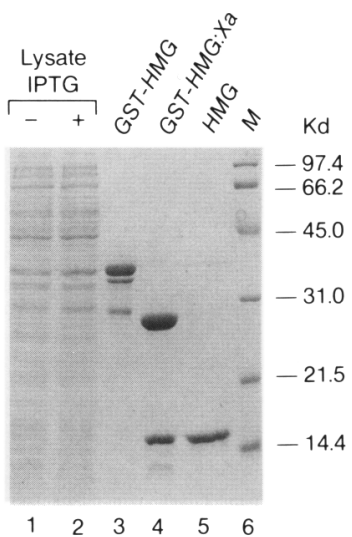

Figure 4. Purification of bacterially produced LEF-HMG domain peptide. SDS-PAGE analysis of the LEF-HMG domain at various stages of purification. Lanes 1 and 2 contain lysate of uninduced and IPTG-induced bacteria carrying a plasmid that encodes a GST/LEF-HMG fusion protein. Affinity-purified GST/LEF-HMG protein before and after cleavage with factor Xa is shown in lanes 3 and 4, respectively. The LEF-HMG domain peptide was purified further by ion-exchange chromatography (lane 5). The sizes of molecular mass markers (M) are indicated in $\mathrm{kD}$. The protein and polypeptide samples were denatured before electrophoresis through a SDS-15\% polyacrylamide gel and stained with Coomassie blue. 
A

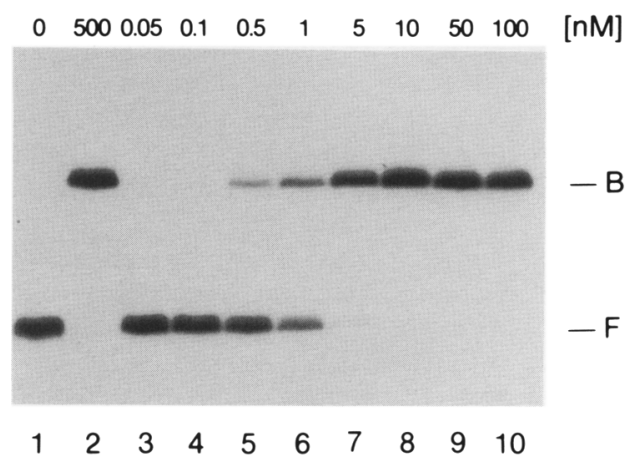

B

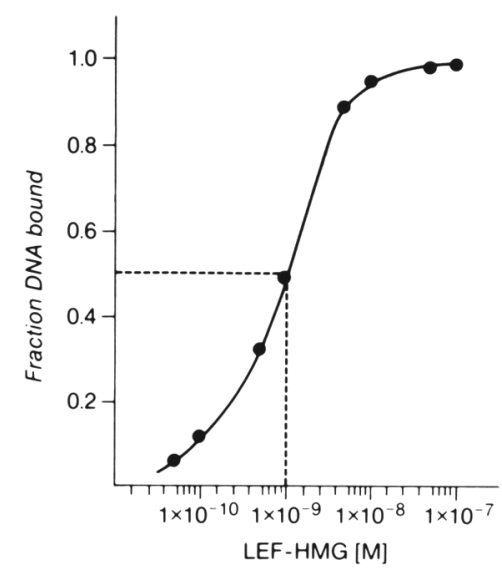

C

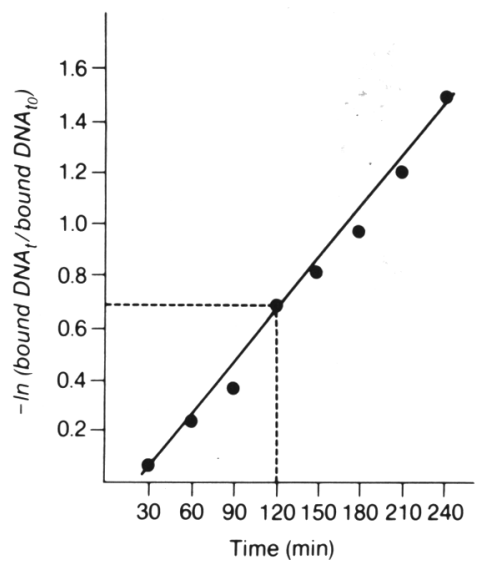

Figure 5. Thermodynamic and kinetic properties of DNA binding by the purified LEF-HMG domain. $(A)$ Analysis of the equilibrium binding of the purified LEF-HMG domain to TCR $\alpha 25$ DNA in an electrophoretic mobility-shift assay (EMSA). Increasing concentrations $\left(k_{d}\right)$ of peptide $(0.05-100 \mathrm{nM})$ was incubated with $10 \mathrm{pM}$ of labeled TCR $\alpha 25$ oligonucleotide (lanes $\left.3-10\right)$. Bound $(\mathrm{B})$ and free $(\mathrm{F})$ DNA were separated by electrophoresis through a native polyacrylamide gel, and the radioactivity in each band was measured on a PhosphorImager (Molecular Dynamics). $(B)$ Determination of the equilibrium dissociation constant $\left(k_{\mathrm{d}}\right)$. The values of radioactivity in bound and free DNA from 4 were used to plot the fraction of bound DNA as a function of the log of LEF-HMG domain peptide concentration. The concentration required for half-maximal binding $(1 \mathrm{nM})$ was taken as an estimate for the $K_{\mathrm{d}} .(C)$ Determination of the dissociation rate constant $\left(k_{\mathrm{d}}\right)$. The stability of the LEF-HMG peptide-DNA complex was assayed by EMSAs in which the preformed complex was incubated in the presence of excess unlabeled competitor DNA (data not shown). Dissociation kinetics were determined by plotting the natural logarithm of the ratio of bound DNA, to bound DNA $\mathrm{to}_{\mathrm{to}}$ as a function of time $\left.\mid 0-4 \mathrm{hr}\right)$, with $k_{\mathrm{d}}$ equaling the slope of the time.

amino acids that are conserved between SRY and LEF-1, we examined the functional role of DNA binding of these and additional evolutionarily conserved amino acids by site-directed mutagenesis of the LEF-HMG domain (Fig. 7A). We also included a mutation that altered a stretch of basic amino acids at the carboxyl terminus of the HMG box. Basic amino acids were previously found to govern the DNA binding of the bZip and bHLH structural motifs (Landschulz et al. 1989; Turner and Tiian 1989; Davis et al. 1990; Voronova and Baltimore 1990). The mutated LEF-HMG boxes, encoding amino acids 287-385 with single or double mutations in evolutionarily conserved codons, were linked to the $3^{\prime}$ end of the GST gene. The GST/LEF-HMG fusion proteins were overexpressed in Escherichia coli and purified by affinity chromatography. The purity and quantity of the fusion proteins were assessed by SDS-PAGE (Fig. 7B). Each protein preparation contained a substantial amount of deg. radation products. These polypeptides most likely represent carboxy-terminal truncations of the fusion proteins because they failed to bind to DNA (data not shown). Each fusion protein preparation was adjusted for a constant amount of the intact protein and examined for binding to the TCR $\alpha 25$ oligonucleotide in an electrophoretic mobility-shift assay (Fig. 7C). The KK298-9EE double mutation, which substituted two glutamate residues for two lysine residues, virtually abolished detectable DNA binding (lane 4). This result suggested that these conserved basic residues are important for high-affinity DNA binding. The
L301T, Y346S, and KK374-5EE mutations also decreased DNA binding significantly, although to a lesser extent (lanes 5,7,8). In contrast, neither the I297L nor the V316L mutation altered DNA binding significantly (lanes 3,6).

We also included in this analysis a truncated form of the wild-type LEF-HMG box comprising amino acids 296-385. The GST fusion protein of this truncated HMG domain bound to TCR $\alpha 25$ DNA with an affinity that was similar to that of the larger HMG box. This further delineates the amino-terminal boundary of the DNAbinding domain to amino acid 296 (lane 9).

To quantitate the effects of the mutations in the LEFHMG box on DNA-binding affinity, we determined the $K_{\mathrm{d}}$ for the interaction of the mutant GST/LEF-HMG fusion proteins with TCR $\alpha 25$ DNA by saturation-binding experiments. In these experiments, the concentration of protein was varied relative to a fixed limiting concentration of probe DNA (data not shown). The $K_{d}$ values of the various mutant protein-DNA complexes were in agreement with the DNA-binding data shown in Figure 7C, with the exception of the values obtained with L301T protein (Table 1). This mutant protein did not bind $>10 \%$ of the TCR $\alpha 25$ oligonucleotide, even at a protein concentration as high as $7 \times 10^{-8} \mathrm{M}$. Likewise, we were unable to obtain $>10 \%$ binding of the KK298-9EE double mutation at concentrations of $8 \times 10^{-7} \mathrm{M}$. It is unclear whether these mutations alter the folding of the majority of peptide molecules or affect their contact with DNA. Nevertheless, the data indicate that the 
A

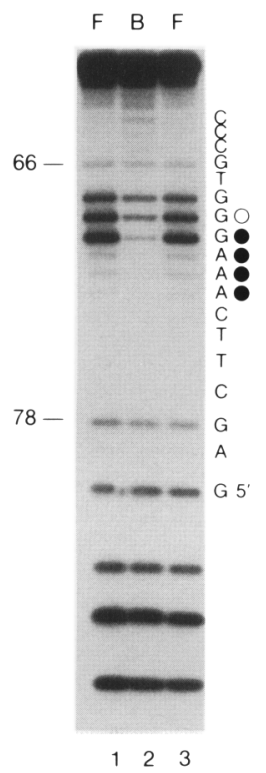

B

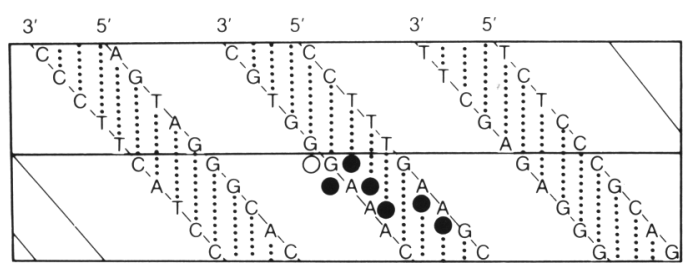

Figure 6. Specific DNA contacts by the LEF-HMG domain. $(A)$ Methylation interference analysis of the TCR $\alpha 25$ oligonucleotide. The TCR $\alpha 25$ oligonucleotide was 5 '-end-labeled on either the noncoding (bottom) strand (lanes 1-3) or coding strand (lanes 4-6), partially methylated with dimethylsulfate. Intact probe was purified by gel electrophoresis and incubated with synthetic LEF-HMG peptide. Bound and free oligonucleotides were separated by an electrophoretic mobility-shift assay, cleaved with piperidine, and electrophoresed through a sequencing type gel. G and A nucleotides that interfere strongly $(O)$ or weakly $(O)$ with binding of the peptide are indicated. $(B)$ Summary of the methylation interference data. The DNA double helix is displayed in a planar representation /Siebenlist and Gilbert 1980). The dotted vertical lines represent the plane of base pairs, and the diagonal lines represent the phosphate backbone. The nucleotide sequence in the region of the LEF-1-binding site is indicated. N7 methyl groups of $G$ residues that interfere with binding of the LEF-HMG peptide are shown in the major groove. N3 methyl groups of A residues that interfere with binding are shown in the minor groove of the DNA double helix.

amino acid conservation between LEF-1 and SRY defines functionally important residues for DNA binding.

\section{Discussion}

The LEF-HMG box encodes a sequence-specific DNA-binding domain

Several lines of evidence identified the HMG-box homology of LEF-1 as a DNA-binding domain. First, aminoand carboxy-terminal truncations of the LEF-1 polypeptide that removed amino acids from the HMG domain abrogated DNA binding. Second, synthetic or purified peptides comprising only the HMG domain of LEF-1 bound DNA in a sequence-specific manner. Third, changes of amino acids in the HMG domain affected the DNA-binding affinity. The boundaries of this protein domain were defined by the analysis of DNA binding with amino- and carboxy-terminally truncated LEF-1 polypeptides, an HMG domain peptide comprising amino acids 288-380, and a GST-LEF-HMG fusion protein containing amino acids 296-385. Amino acid 296 appears to represent the closest amino-terminal boundary compatible with DNA binding because a double mutation of the lysine residues at positions 298 and 299 virtually abrogated binding. The carboxy-terminal boundary of the LEF-HMG domain is less well defined but is located between amino acids 365 and 380 . Inspection of the $\sim 80$ amino-acid HMG domain did not reveal any obvious amphipathic helices, although several regions have the potential to form $\alpha$-helices. However, no obvious structural features can be predicted for the HMG domain, and a structural analysis of both sequence-specific and nonspecific HMG boxes is required to gain insight into the molecular basis of DNA binding by these protein domains.

The amino acid conservation in the HMG box between various members of the family is most pronounced in the amino-terminal region and allowed us to identify candidate residues that are important for DNA binding. Although our mutational analysis is limited, it confirmed the role of evolutionarily conserved amino acids for DNA binding. In particular, a Lys-Glu double mutation at positions 298 and 299 of LEF-1 abrogated the DNA-binding ability of the HMG domain. These two basic residues may function in a manner similar to the stretches of positively charged amino acids that are important for DNA binding by the bZip and bHLH structural motifs (Landschulz et al. 1989; Turner and Tiian 1989; Davis et al. 1990; Voronova and Baltimore 1990). In contrast, a double mutation of the lysine residues at 374 and 375 within a stretch of 7 basic amino acids at the carboxy-terminal end of the HMG box decreased the DNA-binding affinity by a factor of 10 , suggesting a supportive but not essential role for DNA binding. Likewise, changing either amino acid 301 or 346 of LEF-1, both of which are conserved with SRY, decreased the DNAbinding affinity by a factor of 10 .

The interaction of the LEF-HMG domain with DNA is sequence specific by multiple criteria. A TCR $\alpha$ oligonucleotide containing a LEF-1 recognition sequence competed with itself for binding by the LEF-HMG domain, whereas a TCR $\alpha$ oligonucleotide containing a mutated LEF-binding site did not compete. In a DNase I footprint assay, only a specific region within a 100-bp fragment was protected from DNase I digestion. Finally, the methylation interference analysis indicated specific contacts of the LEF-HMG domain with DNA. The sequence-specific DNA binding of the HMG domain of LEF-1 distinguishes this structural motif from the HMG domains of the related proteins hUBF and HMG-1, which appear to bind DNA with low and no specificity, respectively (van Holde 1989; Jantzen et al. 1990). 
A

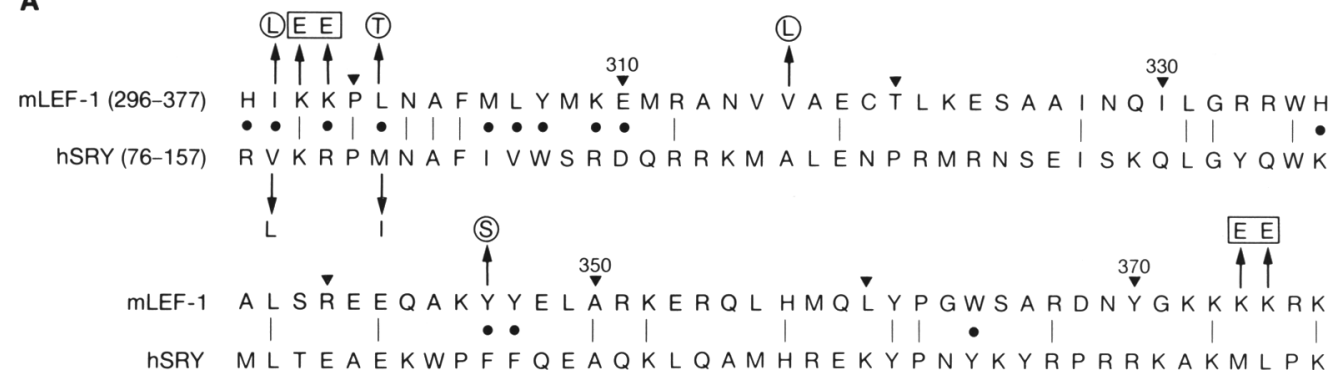

Figure 7. Amino acid conservation between LEF-1 and SRY defines functionally important residues for DNA binding. (A) Amino acid sequence homology of the HMG boxes of murine LEF-1 (Travis et al. 1991) and human SRY (Sinclair et al. 1990). The amino acid positions of the HMG box in each protein are indicated in parentheses. Amino acid identity between LEF-1 and SRY is denoted by vertical lines, and amino acid conservation is indicated by dots. Below the amino acid sequence of SRY, two amino acid changes are indicated that are present in the SRY protein of sex-reversed XY females, carrying a mutated SRY allele (Berta et al. 1990). Above the amino acid sequence of LEF-1, single and double amino acid changes generated by site-directed

B

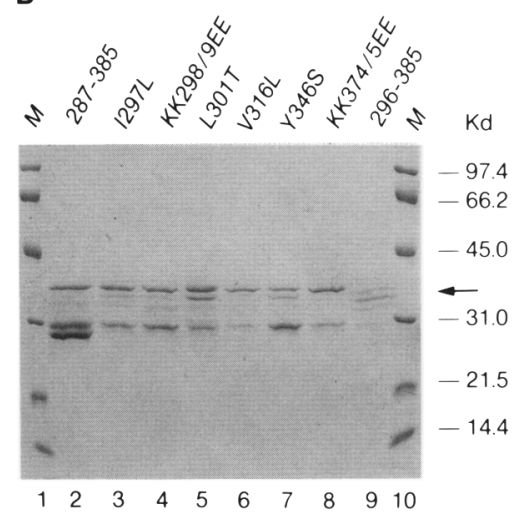

C

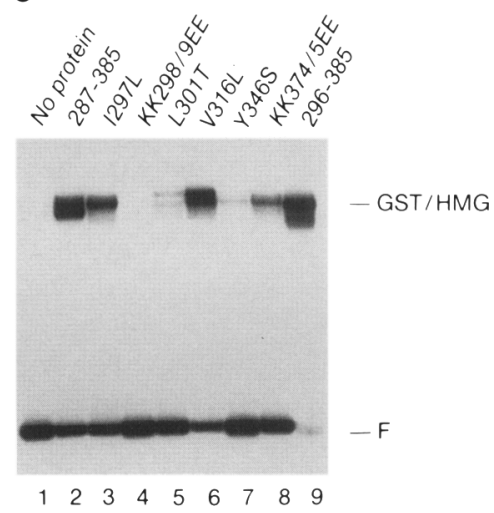
(Me LEF-HMG box (Materials and methods) are shown. (B) Purification of mutant GST/LEF-HMG fusion proteins SDS-PAGE analysis of affinity-purified GST/LEF-HMG fusion proteins containing single or double substitutions of amino acids in the HMG domain of LEF-1. The letter before the number, designating the amino acid position, indicates the amino acid in the wild-type protein and the letter after the number indicates the amino acid of the mutant protein. The mobility of the intact GST/LEF-HMG protein is indicated by an arrow. Faster-migrating polypeptides most likely represent carboxy-terminal degradation products. The sizes of the molecular mass markers $(\mathrm{M})$ are indicated in $\mathrm{kD}$. (C) DNA binding of affinity-purified mutant GST/LEF-HMG fusion proteins One nanogram of mutant fusion proteins was incubated with labeled TCR $\alpha 25$ oligonucleotide in the presence of $1.5 \mathrm{ng}$ of sonicated salmon sperm DNA. The position of the protein-DNA complex is indicated with GST/HMG, and that of free DNA probe with F.

\section{Specificity of DNA binding of HMG box proteins}

One of the intriguing results from our study is the fairly high affinity but modest specificity of the interaction of the LEF-HMG domain with DNA. The specificity of this reaction, as defined by the difference of the $K_{\mathrm{d}}$ for specific versus nonspecific DNA, is $\geqslant 20$ - to 40 -fold and thus, similar to the 100-fold DNA-binding specificity of the Antennapedia homeo domain (Affolter et al. 1990). Nevertheless, it is possible to observe a very high degree of "apparent" specificity in the in vitro binding assays by

Table 1. Binding of wild-type and mutant GST/LEF-HMG fusion proteins to the TCR $\alpha 25$ oligonucleotide

\begin{tabular}{lc}
\hline & \multicolumn{1}{c}{$K_{\mathrm{d}}(\mathrm{M})$} \\
\hline Wild type & $1 \times 10^{-9}$ \\
I297L & $1.7 \times 10^{-9}$ \\
KK298/9EE & $>8 \times 10^{-7 \mathrm{a}}$ \\
L301T & $>7 \times 10^{-8 \mathrm{a}}$ \\
V316L & $1.3 \times 10^{-9}$ \\
Y346S & $1.1 \times 10^{-8}$ \\
KK374/5EE & $1.5 \times 10^{-8}$ \\
\hline
\end{tabular}

${ }^{a}$ Less than $10 \%$ DNA binding was detected at this protein concentration. choosing the appropriate concentrations of protein, specific probe, and nonspecific competitor. The modest difference in the $K_{\mathrm{d}}$ for binding of the LEF-HMG domain to specific and nonspecific DNA, however, raises a serious problem for the recognition of specific sites in the genome. Another problem is raised by the observation that distinct HMG box proteins can apparently recognize the same nucleotide sequence. For example, the protein encoded by the mammalian testis-determining factor gene SRY shares only $25 \%$ of the amino acids in the HMG box with both LEF-1 and TCF-1 but binds the TCF-1 target site 5'-CCTTTGTT (V. Harley, R. Lovell-Badge, and P. Goodfellow, pers. comm.). Likewise, this nucleotide sequence is also recognized by LEF-1 (data not shown). SRY is expressed only in developing testis, whereas LEF-1 and TCF-1 are expressed in lymphocytes. Therefore, an overlapping or even identical DNA-binding specificity of distinct HMG box proteins would present a paradox for a precise cell type-specific gene regulation similar to that noticed for homeo domain proteins (Hayashi and Scott 1990). Three views could provide an explanation for both of these problems.

First, LEF-1 may interact with another protein to increase the specificity of DNA binding. According to this 
view, the $K_{\mathrm{d}}$ for a specific site would be decreased by a cooperative interaction with another DNA-binding protein. We have not yet obtained evidence for such a putative cooperative interaction within a minimal TCR $\alpha$ enhancer fragment; however, it may exist at other LEF-1 target sites in the genome. The specificity of DNA binding by the ubiquitous HMG-box protein hUBF has been reported to increase through an interaction with the protein SL1 (Bell et al. 1990). SL1 is a species-specific determinant that can associate with hUBF to govern transcription from either the mouse or the human rRNA promoter. Although the $K_{\mathrm{d}}$ for the hUBF-DNA versus the hUBF + SLl-DNA complex has not yet been determined, a cooperative interaction between hUBF and SLl was extrapolated from the enhanced protection in a DNase I footprint analysis (Bell et al. 1990). Interestingly, the SRY protein has also been implicated to function in a species-specific manner because ectopic expression of the murine SRY gene, but not the human gene, in genetically female mice resulted in sex conversion (Koopman et al. 1991). Because the amino acid sequence of human and murine SRY proteins is highly conserved in the HMG box, the species-specific function of SRY may relate to an interaction with another protein.

Second, it is possible that the binding site for LEF-1 in the TCR $\alpha$ enhancer is not the "optimal" site. If LEF-1 recognizes another as yet unidentified target nucleotide sequence with a significantly higher affinity, we would expect to identify such preferred binding sites by selection from a pool of oligonucleotides of random sequence. Toward this goal, we incubated a pool of oligonucleotides of random sequence with purified immobilized LEF-HMG domain and selected for high-affinity binding sites by several rounds of binding and washing. We identified several oligonucleotides of comparable or lower affinity than the LEF-1-binding site in the TCR $\alpha$ enhancer, but none with higher affinity (A. Amsterdam and R. Grosschedl, unpubl.). Therefore, we consider the existence of higher affinity-binding sites for the LEF-HMG domain as unlikely.

Third, LEF-1 and possibly other sequence-specific HMG-box proteins may be able to recognize specific sites in the genome because of their high concentration in the nucleus. In Escherichia coli, this scheme appears to account for the recognition of functionally important binding sites by integration host factor (IHF). Although IHF is a sequence-specific DNA-binding protein /Craig and Nash 1984), it can also bind to nonspecific DNA under certain conditions (Bonnefoy and Rouviere-Yaniv 1991). Therefore, the high abundance of $\operatorname{IHF}(20,000 \mathrm{~mol}-$ ecules per cell; M. Ditto and R. Weisberg, pers. comm.) may be important for IHF to find specific sites. Because we have not yet obtained a good estimate of the concentration of LEF-1 in the nucleus, we cannot determine whether this scheme could allow LEF-1 to find functionally important binding sites in the genome.

\section{Features of the HMG domain-DNA interaction}

The interaction between the HMG domain of LEF-1 and a specific nucleotide sequence in the TCR $\alpha$ enhancer has several distinct features. First, the analysis of DNA binding using combinations of full-length and truncated LEF-1 polypeptides suggested that the HMG domain can bind as a monomer. Second, the affinity of the LEFHMG domain for specific DNA is fairly high with a $K_{\mathrm{d}}$ of $1 \times 10^{-9} \mathrm{M}$. Part of this high affinity of the HMG domain is due to the slow dissociation rate of the LEFHMG-DNA complex and a half-life of $2 \mathrm{hr}$. These DNAbinding properties are virtually identical to those of the Antennapedia homeo domain (Affolter et al. 1990). This similarity is extended further by the apparent binding of both the HMG domain and the homeo domain as monomers. Moreover, both the LEF-HMG domain and the Antennapedia homeo domain also have a relatively high general affinity for DNA, suggesting that nonspecific interactions with DNA contribute to the high stability of the peptide-DNA complex. In this respect, both the HMG domain and the homeo domain differ from the prokaryotic helix-turn-helix monomers that are related to homeo domains but bind specific "half-sites" with a very low affinity (Hollis et al. 1988). Third, the representation of the results of a methylation interference analysis in a planar projection diagram indicated that the HMG domain of LEF-1 shows a prominent N3-adenine methylation interference pattern and suggested that the HMG domain contacts a relatively small patch of DNA on one side of the double helix. This interference pattern is consistent with the likely binding of LEF-1 as a monomer.

The N3-adenine methylation interference pattern was not observed previously with the full-length LEF-1 protein because of a lower sensitivity of the assay (Travis et al. 1991). Prominent N3-adenine methylation interference was also observed for binding of TCF-l to the nucleotide sequence $5^{\prime}$-CCTTTGTT /van de Wetering et al. 1991). Although methylation of the N3 position of adenines alters the minor groove of B-form DNA, this interference pattern is difficult to interpret and does not necessarily imply extensive minor groove contacts. For example, methylation interference analysis of DNA binding of the Antennapedia homeo domain revealed significant N3-adenine methylation interference (Affolter et al. 1990). The analysis of the crystal structure of the homeo domain-DNA complex, however, indicated that this structural motif contacts primarily the major groove of DNA by a "recognition" $\alpha$-helix. Only the amino-terminal portion of the homeo domain reaches around DNA and contacts the minor groove /Kissinger et al. 1990). Clearly, the structural analysis of the HMGDNA complex is required to gain insight into the precise contacts between the HMG domain and DNA.

Several other DNA-binding proteins have a prominent N3-adenine methylation interference pattern. The $\alpha$ protein an HMG-I-like protein, which is unrelated to the HMG-1 family of nonhistone chromosomal proteins (Goodwin and Bustin 1988), binds AT-rich sequences with low specificity and shows an extensive N3-adenine methylation interference (Solomon et al. 1986). Likewise, the bacterial IHF falls into this category of pro- 
teins. The methylation interference pattern of IHF was interpreted to suggest that this protein contacts primarily the minor groove of B-form DNA (Yang and Nash 1989). Although the structural basis for the putative interaction of IHF with the minor groove is not understood, it may be related to that of the bacterial histonelike HU proteins that share an extensive homology with IHF (Drlica and Rouviere-Yaniv 1987). HU proteins bind DNA nonspecifically by a pair of $\beta$ sheets, possibly by encircling the double helix (Tanaka et al. 1984). Thus, the eukaryotic HMG-like proteins and prokaryotic HUlike proteins share two features: (1) Both types of proteins show prominent $\mathrm{N} 3$-adenine methylation interference, and (2) both families comprise sequence-specific and nonspecific DNA-binding proteins. However, a more detailed comparative structural and functional analysis will be required to establish whether these evolutionarily distant protein families are structurally or functionally related.

\section{Materials and methods}

Oligonucleotides

The nucleotide sequence of the coding (top) strand of the double-stranded oligonucleotides used as probes or competitors in electrophoretic mobility-shift assays are as follows:

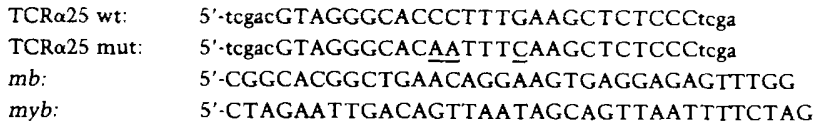

The lowercase letters indicate linker sequences.

The following oligonucleotides were used for mutagenesis. The mutated nucleotide position is underlined. The numbers correspond to the amino acid residue position in the LEF-1coding region (Travis et al. 1991). I297L, 5'-AAGACCTCATCTTAAGAAGCCTCTGAA; KK298/9EE, 5'-AGACCTCATATTGAGGAGCCTCTGAATGCT3'; L301T， 5'-ATTAAGAAGCCTACGAATGCTTTCATG, V316L, 5'-AGCGAATGTCCTAGCTGAGTGCACGCT, Y346S: 5'-CAGGCCAAATCCTATGAACTAGCACGG, KK374/375EE, 5'-TGGCAAGAAGG_AGGAGAGGAAGAGAGAGAA.

\section{In vitro transcription and translation}

DNA fragments comprising different parts of the LEF-1-coding region were cloned into Bluescript plasmid (Stratagene) containing either an initiation codon for amino-terminal deletions or a stop codon for carboxy-terminal deletions. For the generation of the deletion mutants, restriction sites in the LEF-1 cDNA sequence were used (Travis et al. 1991). N25 represents a shorter LEF-1 cDNA clone starting at amino acid position 25 (Travis et al. 1991). Amino-terminal deletion clones were generated by cleavage with StuI(N99), BamHI(N167), NdeI(N244), XmnI(N304), and SmaI(N341). Carboxy-terminal deletion clones were constructed by cleavage with SalI(C384), HhaI(C365), and SmaI/C339), followed by the insertion of stop codons in all three reading frames at the Asp-718 site of the polylinker in Bluescript. Translation of these truncated LEF cDNAs resulted in the addition of 12-17 amino acids encoded by the polylinker. Two micrograms of the various plasmid DNAs was linearized with Asp-718, and in vitro transcription with a T7 RNA polymerase (Boehringer) was performed according to the manufacturer's instructions. The RNA was translated in a wheat germ extract, and $\left[{ }^{35} S\right]$ methionine-labeled products were analyzed on $15 \%$ SDS-PAGE.

Electrophoretic mobility-shift assays, DNase I footprinting, and methylation interference analysis

Electrophoretic mobility-shift assays were performed as described by Travis et al. (1991). Briefly, the DNA-binding reactions were performed for $30-120 \mathrm{~min}$ in $20 \mu \mathrm{l}$ of binding buffer $[50 \mathrm{mM} \mathrm{NaCl}, 20 \mathrm{mM}$ Tris- $\mathrm{HCl}(\mathrm{pH} 7.5), 1 \mathrm{~mm}$ DTT, $1 \mathrm{mM}$ $\mathrm{MgCl}_{2}$, and $50 \mathrm{mg} / \mathrm{ml}$ of BSA] containing $\sim 10,000 \mathrm{cpm}[5$ fmoles) labeled probe, the indicated amounts of sheared salmon sperm DNA, and poly $[\mathrm{d}(\mathrm{I}-\mathrm{C})]$ as nonspecific competitors and the indicated amount of protein or peptide.

The DNase I footprint analysis was performed as described (Travis et al. 1991), with the exception that 10-1000 ng of synthetic LEF-HMG peptide was used for the DNA-binding reaction.

For methylation interference analysis, double-stranded TCR $\alpha 25$ oligonucleotide (Travis et al. 1991) labeled either at the $5^{\prime}$ end of the coding or noncoding strand was methylated with dimethylsulfate (1980). DNA-binding reactions $(40 \mu l)$ were performed using $50 \mathrm{fmoles}$ of the single end-labeled probe, $500 \mathrm{ng}$ of sonicated salmon sperm DNA, and $1.6 \mu \mathrm{g}$ of synthetic LEFHMG domain peptide or $20 \mathrm{ng}$ of purified LEF-HMG domain peptide.

\section{Synthetic LEF-HMG domain peptide}

The synthetic LEF-HMG domain peptide comprising amino acid residues 288-380 was synthesized on an Applied Biosystems Peptide Synthesizer (model 430A), and the product was purified by high-performance liquid chromatography on a $\mathrm{C}_{18}$ Vydac column. The quality of the peptide was analyzed by SDSPAGE.

\section{PCR-mediated construction of LEF-HMG domain expression clones}

DNA fragments containing LEF-1-coding regions $287-385$ or 296-385 were obtained by polymerase chain reaction (PCR) amplification (Saiki et al. 1988). Amplification was performed with the LEF- 1 cDNA as template and the following primers at $1 \mu \mathrm{M}$ each: one common antisense primer, 5'-TTATTACGTCGACTCCTGTAGCTTCTC, containing two in-frame TAA stop codons for both constructs and sense primers: $5^{\prime}$-CGCATATGAGAAAGGAGCAGGAGCCCAAA for amino acid position 287 and 5 '-CGCATATGCATATTAAGAAGCCTCTGAAT for amino acid position 296. PCR was performed in 25 cycles of 1 $\min$ at $94^{\circ} \mathrm{C}$, followed by $1 \mathrm{~min}$ at $45^{\circ} \mathrm{C}$ and $2 \mathrm{~min}$ at $72^{\circ} \mathrm{C}$. The final extension was done at $72^{\circ} \mathrm{C}$ for $10 \mathrm{~min}$. The amplified products were purified on Qiagen columns (Qiagen), phosphorylated at the $5^{\prime}$ end, and ligated into the Smal site of plasmid Bluescript M13 + KS (Stratagene). After transforming Escherichia coli strain DH5 $\alpha$ (BRL), the recombinant clones were identified by restriction analysis and DNA sequencing.

\section{Expression and purification of LEF-HMG domain polypeptide}

The HMG domain (amino acids $287-385$ of LEF-1) was expressed as GST fusion protein in Escherichia coli strain JR500 generated by Rouviere-Yaniv and kindly provided by R. Kahmann. Fusion protein expression and purification were essentially as described by Smith and Johnson (1988). The gene construct encoding the GST/LEF-HMG fusion protein was generated by inserting an amplified BamHI-EcoRI DNA fragment of 
LEF-1 (see above) into the expression vector pGEX-3X (Pharmacia). The in-frame fusion with the coding region for GST was verified by DNA sequencing. Fusion protein expression was induced by the addition of $0.7 \mathrm{mM}$ IPTG (isopropyl- $\beta$-D-thiogalactopyranoside) for $90 \mathrm{~min}$. The bacterial cells were harvested by centrifugation and resuspended in cold lysis buffer $250 \mathrm{~mm}$ $\mathrm{NaCl}, 100 \mathrm{~mm}$ EDTA, $1 \mathrm{mM}$ DTT, and $10 \mathrm{~mm}$ sodium phosphate (pH 7.0)|containing $2 \mathrm{~mm}$ phenylmethylsulfonyl fluoride (PMSF), $50 \mu \mathrm{M}$ pepstatin A, and $50 \mu \mathrm{M}$ leupeptin as protease inhibitors. Cells were lysed by passing the suspension twice through a French press. Fusion proteins were purified from a cleared lysate by glutathione-Sepharose affinity chromatography and released from the beads with $50 \mathrm{~mm}$ glutathione, according to the manufacturer's instructions (Pharmacia).

The fusion protein was concentrated, and the GST carrier was clipped off by protease cleavage (blood coagulation factor $\mathrm{Xa}$; New England Biolabs). Owing to the position of the cleavage site in the fusion protein, the released HMG domain polypeptide contains 6 additional amino acid residues at the amino terminus (GIPPHM). The cleavage products were adjusted to 20 $\mathrm{mM} \mathrm{NaCl}, 1 \mathrm{~mm} \mathrm{DTT}$, and $20 \mathrm{~mm}$ Tris- $\mathrm{HCl}(\mathrm{pH} 7.5)$ and subjected to SP-5PW (Waters) ion-exchange chromatography. The column was developed with a linear concentration gradient from $20 \mathrm{~mm}-1 \mathrm{M} \mathrm{NaCl}$. Fractions containing the LEF-HMG domain peptide were concentrated and dialyzed against $100 \mathrm{~mm}$ $\mathrm{NaCl}, 1 \mathrm{~mm}$ DTT, $20 \mathrm{~mm}$ Tris- $\mathrm{HCl}(\mathrm{pH} 7.5)$, and $10 \%$ glycerol.

\section{Construction of LEF-HMG domain mutants}

Oligonucleotide-directed construction of mutations within the LEF-HMG domain (amino acids 287-385) was performed using the pMac plasmid system developed by Stannsens et al. (1989). The coding region for the HMG domain was isolated from the pGEX-HMG296 plasmid by cleavage with BamHI and EcoRI and inserted into plasmid pMa5-10. Gapped-duplex DNAs consisting of single-stranded pMa5-10HMG and double-stranded pMc5-10 cleaved with $B a m H I$ and EcoRI were annealed with the oligonucleotides listed above, and the gap was filled by Klenow enzyme. The mutant genotype was verified by DNA sequencing of the entire LEF-HMG domain-coding region to ensure that no additional mutations had occurred during the mutagenesis. DNA fragments containing defined mutations in the coding region were inserted into the plasmid pGEX-3X for fusion protein expression. Expression and affinity purification of the fusion proteins containing the mutant LEF-HMG domain were performed as described above.

\section{Equilibrium and kinetic DNA-binding measurements}

All equilibrium and kinetic constants were calculated from several experiments. The equilibrium dissociation constant was defined by the equation $K_{\mathrm{d}}=[\mathrm{DNA}] \cdot[\mathrm{HMG}] \cdot[\mathrm{DNA} \cdot \mathrm{HMG}]$, in which [DNA] is the concentration of free DNA, $[\mathrm{HMG}]$ is the concentration of free HMG domain polypeptide, and [DNA - HMG] is the concentration of the DNA-protein complex. In each experiment the protein concentration was kept at least 100 -fold in excess over DNA, allowing the approximation, concentration of free protein equals that of total protein. The determination of the equilibrium-binding constant was performed by saturation-binding experiments in which the concentration of peptide was varied relative to a fixed and limiting concentration of DNA probe or, alternatively, the concentration of protein and DNA probe were varied without altering their ratio (Liu-Johnson et al. 1986).

The dissociation rate constant was derived by determining $k_{\mathrm{d}} \mathrm{t}=\ln$ ([HMG-DNA $\left.\left.\mathrm{t}\right] /\left[\mathrm{HMG} \cdot \mathrm{DNA}_{\mathrm{to}}\right]\right)$. A total of $10 \mathrm{fmoles}$ of end-labeled double-stranded oligonucleotide comprising the LEF-binding site was incubated in $20 \mu \mathrm{l}$ of binding buffer with 8 fmoles of purified LEF-HMG domain peptide at room temperature for $1 \mathrm{hr}$. Two hundred fifty-fold molar excess of unlabeled competitor oligonucleotide was added at time intervals of 15 min, up to $4 \mathrm{hr}$, and the complexes were analyzed on nondenaturing polyacrylamide gels. The gels were dried, and the value of [DNA]/[DNA - HMG] was determined by measuring the ratio of the radioactivity in free and bound DNA on a PhosphorImager (Molecular Dynamics).

\section{Acknowledgments}

We are grateful to Chris Turk (HHMI/UCSF peptide facility) for the synthesis of the LEF-HMG peptide. We thank Andrew Vershon and Alexander Johnson for valuable discussions and Elizabeth Blackburn, Jim Hagman, and Tom Komberg for critical comments on the manuscript. We are also grateful to Gail Mosley for the expert preparation of this manuscript. K.G. is supported by a postdoctoral fellowship from the Deutsche Forschungsgemeinschaft (DFG). This work was supported by funds from the Howard Hughes Medical Institute.

The publication costs of this article were defrayed in part by payment of page charges. This article must therefore be hereby marked "advertisement" in accordance with 18 USC section 1734 solely to indicate this fact.

\section{References}

Affolter, M., A. Percival-Smith, M. Muller, W. Leupin, and W.J. Gehring. 1990. DNA binding properties of the purified Antennapedia homeo domain. Proc. Natl. Acad. Sci. 87: 40934097.

Bell, S.P., H.-M. Jantzen, and R. Tjian. 1990. Assembly of alternative multiprotein complexes directs rRNA promoter selectively. Genes \& Dev. 4: 943-954.

Berta, P., J.R. Hawkins, A.H. Sinclair, A. Taylor, B.L. Griffiths, P.N. Goodfellow, and M. Fellous. 1990. Genetic evidence equating SRY and the testis-determining factor. Nature 348: $448-450$.

Bonnefoy, E. and J. Rouviere-Yaniv. 1991. HU and IHF, two homologous histone-like proteins of Escherichia coli, form different protein-DNA complexes with short DNA fragments. EMBO I. 10: 687-696.

Craig, N.L. and H.A. Nash. 1984. Escherichia coli integration host factor binds to specific sites in DNA. Cell 39: 707-716.

Davis, R.L., P.F. Cheng, A.B. Lassar, and H. Weintraub. 1990. The myoD DNA binding domain contains a recognition code for muscle-specific gene activation. Cell 60: 733-746.

Drlica, K. and J. Rouviere-Yaniv. 1987. Histonelike proteins of bacteria. Microbiol. Rev. 51: 301-319.

Gilbert, W., A. Maxam, and A. Mirzabekow. 1976. Contacts between the Lac repressor and DNA revealed by methylation. In Control of ribosome synthesis (ed. N.C. Kjeldgaard and O. Maaloe), pp. 139-148. Academic Press, New York.

Goodwin, G. and M. Bustin. 1988. The HMG proteins and their genes. In Architecture of eukaryotic genes (ed. G. Kahl\}, pp. 187-205. VCH Press, Weinheim, Germany.

Gubbay, J., J. Collignon, P. Koopman, B. Capel, A. Economou, A. Munsterberg, N. Vivian, P. Goodfellow, and R. Lovell-Badge. 1990. A gene mapping to the sex-determining region of the mouse $\mathrm{Y}$ chromosome is a member of a novel family of embryonically expressed genes. Nature 346: 245-250.

Hayashi, S. and M.P. Scott. 1990 . What determines the specificity of action of Drosophila homeo domain proteins? Cell 
63: $883-894$.

Ho, I.-C., L.-H. Yang, G. Morle, and J.M. Leiden. 1989. A T-cellspecific transcriptional enhancer element $3^{\prime}$ of $\mathrm{C} \alpha$ in the human T-cell receptor $\alpha$ locus. Proc. Natl. Acad. Sci. 86: 6714-6718.

Hollis, M., D. Valenzuela, D. Pidi, R. Wharton, and M. Ptashne. 1988. A repressor heterodimer binds to a chimeric operator. Proc. Natl. Acad. Sci. 85: 5834-5858.

Jantzen, H.-M., A. Admon, S.P. Bell, and R. Tjian. 1990. Nucleolar transcription factor hUBF contains a DNA-binding motif with homology to HMG proteins. Nature 344: 830-836.

Johnson, P.F. and S.L. McKnight. 1989. Eukaryotic transcriptional regulatory proteins. Annu. Rev. Biochem. 58: 799839.

Kelly, M., J. Burke, M. Smith, A. Klar, and D. Beach. 1988. Four mating-type genes control sexual differentiation in the fission yeast. EMBO I. 7: 1537-1547.

Kissinger, C.R., L. Beisha, E. Martin-Blanco, T.B. Kornberg, and C.O. Pabo. 1990. Crystal structure of an engrailed homeo domain-DNA complex at $2.8 \mathrm{~A}$ resolution: A framework for understanding homeo domain-DNA interactions. Cell 63: $579-590$.

Klug, A. and D. Rhodes. 1987. "Zinc-fingers": A novel protein motif for nucleic acid recognition. Trends Biochem. Sci. 12: 464-469.

Koopman, P., J. Gubbay, N. Vivian, P. Goodfellow, and R. Lovell-Badge. 1991. Male development of chromosomally female mice transgenic for Sry. Nature 351: 117-121.

Landschulz, W.H., P.F. Johnson, and S.L. McKnight. 1988. The leucine zipper: A hypothetical structure common to a new class of DNA binding proteins. Science 240: 1759-1764.

- 1989. The DNA binding domain of the rat liver nuclear protein C/EBP is bipartite. Science 243: 1681-1688.

Liu-Johnson, H.-N., M.R. Gartenberg, and D.M. Crothers. 1986. The DNA binding domain and bending angle of Escherichia coli CAP protein. Cell 47: 995-1005.

Milatovitch, A., A. Travis, R. Grosschedl, and U. Francke. 1991. Gene for lymphoid enhancer-binding factor 1 (LEF1) mapped to human chromosome $4(\mathrm{q} 23-\mathrm{q} 25)$ and mouse chromosome 3 near Egf. Genomics 11: 1040-1048.

Mitchell, P.J. and R. Tiian. 1989. Transcriptional regulation in mammalian cells by sequence specific DNA binding proteins. Science 245: 371-378.

Murre, C., P.S. McCaw, and D. Baltimore. 1989. A new DNA binding and dimerization motif in immunoglobulin enhancer binding, daughterless, MyoD, and myc proteins. Cell 56: 777-783.

Oosterwegel, M., M. van de Wetering, D. Dooijes, L. Klomp, A. Winoto, K. Georgopoulos, F. Meijlink, and H. Clevers. 1991. Cloning of murine TCF-1, a T cell-specific transcription factor interacting with functional motifs in the CD3- $\epsilon$ and TCR- $\alpha$ enhancers. I. Exp. Med. 173: 1133-1142.

Pabo, C.O. and M. Lewis. 1982. The operator-binding domain of $\lambda$ repressor: Structure and DNA recognition. Nature 298: 443-447.

Parisi, M.A. and D.A. Clayton. 1991. Similarity of human mitochondrial transcription factor 1 to high mobility group proteins. Science 252: 965-969.

Saiki, R.K., D.H. Gelfand, S. Stoffel, S.J. Scharf, R. Higuchi, G.T. Horn, K.B. Mullis and H.A. Erlich. 1988. Primer-directed enzymatic amplification of DNA with a thermostate DNA polymerase. Science 239: 487-491.

Siebenlist, U. and W. Gilbert. 1980. Contacts between Escherichia coli RNA polymerase and an early promoter of phage T7. Proc. Natl. Acad. Sci. 77: 122-126.

Sinclair, A.H., P. Berta, M.S. Palmer, J.R. Hawkins, B.L. Grif- fiths, M.J. Smith, J.W. Foster, A.-M. Frischauf, R. LovellBadge, and P.N. Goodfellow. 1990. A gene from the human sex-determining region encodes a protein with homology to a conserved DNA-binding motif. Nature 346: 240-244.

Smith, D.B. and K.S. Johnson. 1988. Single-step purification of polypeptides in Escherichia coli as fusions with glutathioneS-transferase. Gene 67: 31-40.

Solomon, M.J., F. Strauss, and A. Varshavsky. 1986. A mammalian high mobility group protein recognizes any stretch of six A-T base pairs in duplex DNA. Proc. Natl. Acad. Sci. 83: $1276-1280$.

Staben, C. and C. Yanofsky. 1990. Neurospora crassa, a matingtype region. Proc. Natl. Acad. Sci. 87: 4917-4921.

Stannsens, P., C. Opsomer, Y.M. McKeown, W. Kramer, M. Zabeau, and H.-J. Fritz. 1989. Efficient oligonucleotide-directed construction of mutations in expression vectors by the gapped-duplex DNA method using alternating selectable marker. Nucleic Acids Res. 17: 4441-4454.

Sun, X.-H. and D. Baltimore. 1991. An inhibitory domain of E12 transcription factor prevents DNA binding in E12 homodimers but not in E12 heterodimers. Cell 64: 459-470.

Tanaka, I., K. Appelt, J. Dijk, S.W. White, and K.S. Wilson. 1984. 3-A resolution structure of a protein with histone-like properties in prokaryotes. Nature 310: 376-381.

Travis, A., A. Amsterdam, C. Belanger, and R. Grosschedl. 1991. LEF-1, a gene encoding a lymphoid-specific protein with an HMG domain, regulates $T$-cell receptor $\alpha$-enhancer function. Genes \& Dev. 5: 880-894.

Turner, R. and R. Tjian. 1989. Leucine repeats and an adjacent DNA binding domain mediate the formation of functional cFos-cJun heterodimers. Science 243: 1689-1694.

van de Wetering, M., M. Oosterwegel, D. Dooijes, and H. Clevers. 1991. Identification and cloning of TCF-1, a T lymphocyte-specific transcription factor containing a sequence-specific HMG box. EMBO I. 10: 123-132.

van Holde, K.E. 1989. Chromatin (ed. A. Rich). Springer-Verlag Press, New York.

Voronova, A. and D. Baltimore. 1990. Mutations that disrupt DNA binding and dimer formation in the E47 helix-loophelix protein map to distinct domains. Proc. Natl. Acad. Sci. 87: 4722-4726.

Waterman, M.L., W.H. Fischer, and K.A. Jones. 1991. A thymusspecific member of the HMG protein family regulates the human T-cell receptor C $\alpha$ enhancer. Genes \& Dev. 5: 656669.

Winoto, A. and D. Baltimore. 1989. A novel, inducible and T cell-specific enhancer located at the $3^{\prime}$ end of the $T$ cell receptor $\alpha$ locus. EMBO /. 8: 729-733.

Yang, C.-C. and H. Nash. 1989. The interaction of E. coli IHF protein with its specific binding sites. Cell 57: 869-880. 


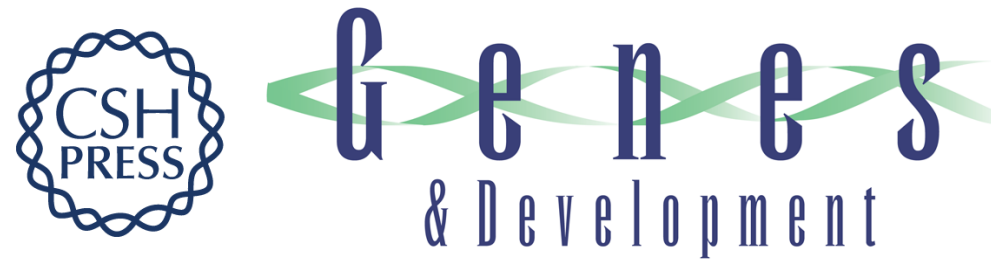

\section{DNA-binding properties of the HMG domain of the lymphoid-specific transcriptional regulator LEF-1.}

$K$ Giese, A Amsterdam and R Grosschedl

Genes Dev. 1991, 5:

Access the most recent version at doi:10.1101/gad.5.12b.2567

References This article cites 42 articles, 18 of which can be accessed free at:

http://genesdev.cshlp.org/content/5/12b/2567.full.html\#ref-list-1

License

Email Alerting

Service

Receive free email alerts when new articles cite this article - sign up in the box at the top right corner of the article or click here.

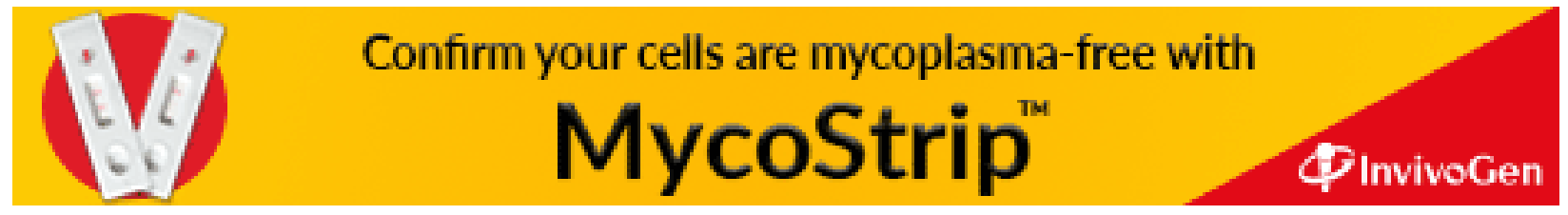

